\title{
Frequency of Transfusion Transmitted Infection Among Blood Donors at Specialized Tertiary Care Hospital in Bangladesh
}

\author{
Ferdous $\mathrm{Ara}^{1}$, Zubaida Nasreen², Md Aminul Islam³, Md.Abdullah Yusuf ${ }^{4}$, \\ Mohammad Syaeed Hassan ${ }^{5}$, Sheikh Farjana Sonia ${ }^{6}$ \\ ${ }^{1}$ Assistant Professor, Dept. of Transfusion Medicine, National Institute of Neurosciences, Dhaka,Bangladesh; \\ ${ }^{2}$ Medical Officer, Dept. of Transfusion Medicine,National Institute of Neurosciences, Dhaka, Banglasesh; \\ ${ }^{3}$ Medical Officer, Dept. of Transfusion Medicine,National Institute of Neurosciences, Dhaka, Banglasesh; \\ ${ }^{4}$ Assistant Professor, Dept. of Microbiology, National Institute of Neurosciences, Dhaka,Bangladesh; ${ }^{5}$ Junior \\ Consultant, Dept. of Neurology, National Institute of Neurosciences, Dhaka, Bangladesh; \\ ${ }^{6}$ Assistant Professor, Dept. of Paediatrics, MARKS Medical College, Dhaka, Bangladesh.
}

Received on: 24 July 2014; Reviewed on: 26 September 2014; Published on: 1 January 2015

\begin{abstract}
Background: Blood transfusion is associated with a number of complications. Transfusion transmitted infections (TTI) are one of the major health problem in Bangladesh. Objective: The objective of the present study was to assess the status of transfusion transmitted infections among the apparently healthy donors. Methods: This study we carried out among 585 blood donors in the transfusion medicine department from April 2013 to March 2014 at National Institute of Neurosciences (NINS) and Hospital in Dhaka, Bangladesh. All the samples were screened for hepatitis B surface antigen (HBsAg), hepatitis C virus (HCV), human immunodeficiency virus (HIV) 1 and 2, venereal disease research laboratory test (VDRL) and malaria to see the prevalence of TTI. Results: Prevalence of hepatitis B virus (HBV), HCV, and syphilis were $1.20,0.68$ and $0.34 \%$ respectively. No blood donor tested showed positivity for malarial parasite and HIV. Conclusion: Mandatory screening of donated blood and use of sensitive screening test should be done to reduce TTI in Bangladesh. [J Natl Inst Neurosci Bangladesh 2015;1(1): 12-14]
\end{abstract}

Keywords: Transfusion transmitted infection, Blood donors, Prevalence, HPV, HPV.

Corresponding author: Dr. Ferdous Ara MBBS, MTM Assistant Professor, Dept. of Transfusion Medicine, National Institute of Neurosciences \& Hospital, Dhaka, Bangladesh, Email: ferdous_ara.shimu@yahoo.com; Cell. No.:+8801712103399

Conflict of interest: Authors declared no conflict of interest

Funding of the study: None

Contribution of the authors: FA, ZN, MAI were contributed from protocol preparation to data collection. MAY, MSH, SFS has prepared the manuscript and revised by them.

How to cite this article: Ara F, Nasreen Z, Islam MA, Yusuf MA, Hassan MS, Sonia SF. Frequency of Transfusion Transmitted Infection Among Blood Donors at Specialized Tertiary Care Hospital in Bangladesh, J Natl Inst Neurosci Bangladesh 2015;1(1): 12-14

\section{Introduction}

Neurological illness has been found associated with transfusion of blood and blood components saves millions of lives world wide each year. It is well-known that blood transfusion is associated with a large number of complications. In developing countries like Bangladesh blood safety remains an issue of major concern. Now-a-days in Bangladesh routine screening of healthy blood donors is done for hepatitis B virus (HBV), hepatitis $\mathrm{C}$ virus (HCV), human immunodeficiency virus (HIV), syphilis and malaria. These strategies have been extremely effective, but transmission of diseases still occurs ${ }^{1,2}$.

Hepatitis-B virus infection results in broad spectrum of disease from sub-clinical infection to fulminate hepatitis. It can progress to chronic active hepatitis, cirrhosis of liver and hepatocellular carcinoma. Globally more than one million deaths occur from complication of HBV infection every year ${ }^{3}$. Hepatitis C Virus (HCV) is emerging as one of the major health problem in Bangladesh. About 3\% of the world's population is infected by this virus accounting a total of 170 million HCV infected persons globally ${ }^{4}$. The long-term risk of developing cirrhosis and hepatocellular carcinoma is greater in $\mathrm{HCV}$-infected individual than those infected with HBV.

HIV is one of the human retroviruses that preferentially infects and kills helper (CD4) T lymphocytes, resulting in the loss of cell mediated immunity and a high probability that the host will develop opportunistic infections ${ }^{5}$. Treponema pallidum causes syphilis. T. pallidum is transmitted from spirochete containing lesions of skin or mucous membrane (eg, genitalia, mouth \& rectum) of an infected person to other persons by intimate contact. It can also be transmitted from pregnant women to their fetuses ${ }^{6}$.

Malaria is caused by four Plasmodia species of which P. vivax and P. falciparum are more common causes of malaria in Bangladesh. Worldwide malaria is one of the 
most common infectious diseases and a leading cause of death. This study was undertaken to know the prevalence of TTI among blood donors.

\section{Methodology}

This retrospective study was carried out in the department of Transfusion Medicine between April 2013 to March 2014 for a period of one year at National Institute of Neurosciences and Hospital in Dhaka, Bangladesh. Blood samples were collected in pre-labeled pilot tube during collection of blood. Serum was separated from the clotted blood. The study included all the donors pretested blood grouping, $\mathrm{Rh}$ factor and cross matching with the blood of their respective recipient admitted in different wards of NINS. Detection of HBsAg, anti HCV and anti HIV were done by ICT. For screening of syphilis Rapid Precipitation Reaction (RPR) was carried out. Detection of malaria was done by ICT method.

\section{Results}

The total number of blood donors was 585. 379 (64.8\%) were relative donor and $206(35.2 \%)$ were voluntary donor. Most donors were male (90.6\%) and rest 55 (9.4\%) were female. The age range of the donors was from 18 to 57 years (table 1).

Table 1: Distribution of blood donors by age groups

\begin{tabular}{lcc}
\hline Age group (years) & Frequency & Percentage \\
\hline $18-27$ & 285 & 49 \\
$28-37$ & 224 & 38 \\
$38-47$ & 70 & 12 \\
$48-57$ & 6 & 1 \\
\hline
\end{tabular}

Prevalence of hepatitis B virus (HBV), HCV, and syphilis were $1.20,0.68$ and $0.34 \%$ respectively. No blood donor tested showed positivity for malarial parasite and HIV.

Table 2: Distribution of blood donors by sex

\begin{tabular}{lcc}
\hline Sex & Frequency & Percentage \\
\hline Male & 530 & 90.6 \\
Female & 55 & 9.4 \\
\hline
\end{tabular}

\section{Discussion}

Studies in the West have shown that the estimated risk of transfusion-transmitted HIV, HCV and to a lesser extend HBV infection via blood products is very $\operatorname{low}^{7-8}$. This is not same in developing countries, like Bangladesh. In the present study, the prevalence of HBsAg was 1.196\%. The prevalence of HBsAg in a study in Khulna Medical College Hospital, Khulna was $1.39 \%{ }^{9}$. In another study in Sir Salimullah Medical College, Dhaka the prevalence was $2.19 \%{ }^{10}$. Seroprevalence of HBsAg in various other Indian studies has been shown to range between 1.86 and $4 \%{ }^{11-12}$. Seroprevalence of HBsAg in various studies in Pakistan has been shown to range between 1.55 and $8.4 \%{ }^{13-14}$.
In the present study the prevalence of seropositivity for anti$\mathrm{HCV}$ was $0.684 \%$. The prevalence of anti-HCV in a study in Khulna Medical College Hospital, Khulna was $0.024 \%{ }^{9}$.

Table 3: Distribution of blood donors by occupation

\begin{tabular}{lcc}
\hline Occupation & Frequency & Percentage \\
\hline Student & 199 & 34 \\
Service & 209 & 36 \\
Business & 89 & 15 \\
Others & 88 & 15 \\
Total & $\mathbf{5 8 5}$ & $\mathbf{1 0 0}$ \\
\hline
\end{tabular}

In another study in Sir Salimullah Medical College, Dhaka the prevalence was $0.25 \%{ }^{10}$. The global prevalence of chronic $\mathrm{HCV}$-infection is estimated to be approaching 3\%. Extremely low anti-HCV prevalence $0 \%$ has been reported among the blood donors is UK and Scandinavia. The highest prevalence $(28 \%)$ has been reported in Egypt ${ }^{15}$. Indian studies indicate that seroprevalence of HCV ranges between 0.4 and $1.09 \%{ }^{11=12}$. Several studies in Pakistan showed that the seroprevalence of $\mathrm{HCV}$ ranges between 0.07 and $4.9 \%{ }^{13-14}$

Table 4: Distribution of blood donors by types

\begin{tabular}{lcc}
\hline Type of blood donor & Frequency & Percentage \\
\hline Voluntary & 206 & 35.2 \\
Relative & 379 & 64.8 \\
\hline
\end{tabular}

The prevalence of HIV seropositivity was $0.0 \%$. The prevalence of HIV in a study in Khulna Medical College Hospital, Khulna was $0.008 \%{ }^{9}$. In another study in Sir Salimullah Medical College, Dhaka the prevalence was $0.08 \%{ }^{10}$. The HIV seroprevalence in Indian scenario has been reported between 0.2 and $1 \%{ }^{16-17}$. Two studies in Pakistan showed the prevalence of HIV $0.0 \%{ }^{13-14}$.

In the present study, the VDRL reactivity was $0.341 \%$. The prevalence of HBsAg in a study in Khulna Medical College Hospital, Khulna was $0.00 \%{ }^{9}$. In another study in Sir Salimullah Medical College, Dhaka the prevalence was $0.17 \%{ }^{10}$.

Table 5: Positive cases among the donors of Transfusion Medicine Unit of NINS $(\mathbf{n}=585)$

\begin{tabular}{lcc}
\hline Screening Tests & Frequency & Percentage \\
\hline HBV (HBsAg) & 7 & 1.196 \\
Anti HCV & 4 & 0.684 \\
VDRL (RPR) & 2 & 0.341 \\
Malarial parasite & 0 & 0.00 \\
Anti HIV & 0 & 0.00 \\
\hline
\end{tabular}

\section{Conclusion}

In the present study, incidence of HBsAg seropositivity was found to be the highest as compared with other transfusiontransmitted infection. HIV infection is a major public health problem world wide but it is still not common in Bangladesh, so attention should be paid toward the prevention of Hepatitis $\mathrm{B}$ and $\mathrm{C}$ virus as well as HIV. 
Therefore, with the implementation of strict donor selection criteria, mandatory screening of donated blood and use of sensitive laboratory screening tests, it may be possible to reduce the incidence of TTI in Bangladesh.

\section{References}

1. Dodd RY, Notari EP, Stamer SL. Current prevalence and incidence of infectious disease markers and estimated window-period risk in the American Red Cross Blood Donor population. Transfusion 2002; 42:975-79. 2. HG. Will blood transfusion ever be safe enough? JAMA 2000; 284:238-40.

3. Kane M. Primary hepatocellular carcinoma and cirrhosis of liver resulting from. Chr. Hepatitis-B virus infection. Vaccine 1995; 13:S47.

4. WHO Global surveillance and control of hepatitis-C. Report of a WHO consultation organized in collaboration with the viral hepatitis prevention board, Antwerp, Belgium. J Viral Hepat 1999; 6 : 35-47.

5. Population Report. Controlling sexually transmitted disease series, 1993; 9: 1-15. 6. Husain M, Islam MN, Sultan M, Prevalence of HBV, HCV, HIV \& syphilis markers in pregnant women in Bangladesh. Journal of BSMMU $1998 ; 13: 17$

7. Alvarez M, Oyonarte S, Rodriguez PM, Hernandez JM. Estimated risk of transfusion-transmitted viral infections in Spain. Transfusion 2002; 42:994-98.

8. Pomper GJ, Wu Y, Synder EL. Risks of transfusion-transmitted infections. Curr Opin Hematol 2003; 10:412-18.

9. Ahmed MU, Begum HA, Hossain T, Chakraborty P. Prevalence of Transfusion Transmitted Infection among Blood Donors. JAFMC
Bangladesh. Vol 5, No 1 (June) 200904.

10. Shasanka Kumar Saha, Ranjit Kumar Banik, Mili Rani Saha, Munshi M Habibullah, Mamun-Al-Mahtab. Prevalence of Transfusion Transmitted Infection in Healthy Blood Donors in Sir Salimullah Medical College. Euroasian Journal of Hepato-Gastroenterology, July-December 2011;1(2):68-70

11. Chandrasekaran S, Palaniappan N, Krishnan V, Mohan G, Chandrasekaran N. Relative prevalence of hepatitis B viral markers and hepatitis $\mathrm{C}$ virus antibodies (anti-HCV) in Madurai, South India. Indian Journal of Medical Sciences 2000; 547:270-73.

12. Srikrishna A, Sitalakshmi S, Damodar P. How safe are our safe donors? Indian Journal of Pathology and Microbiology 1999; 424:411-16.

13. Khan MA, Rehman A, Ashraf M, Ali A, Ditta A. Prevalence of HBV, HCV and HIV in blood donors at Liaquatpur. Professional Med J 2006; 13:23-26.

14. Mahmood MA, Khawar S, Anjum AH, et al. Prevalence of Hepatitis B, $\mathrm{C}$ and HIV infection in blood donors of Multan region. Ann King Edward Med Coll 2004; 10:459-61.

15. Armstrong G, Alter M, McQuillang, et al. The past incidence of hepatitis $\mathrm{C}$ virus infection; implication for the future burden of chronic liver disease in United States. Hematol 2000; 31:777-82.

16. Garg S, Mathur DR, Garg DK. Comparison of seropositivity of HIV, HBV, $\mathrm{HCV}$ and syphilis in replacement and voluntary blood donors in Western India. Indian Journal of Pathology and Microbiology 2001; 444:409-12.

17. Paramjit K, Basu S. Transfusion-transmitted infections: Existing and emerging pathogens. Journal of Post Graduate Medicine 2005; 51:146-51. 